\title{
Literatura infantil em acesso aberto: análise das vantagens e desafios
}

\author{
Children's literature in open access: analysis of the advantages and challenges
}

\author{
Clarice Fortkamp Caldin \\ Doutorado em Literatura pela Universidade Federal de Santa Catarina - UFSC. \\ Professor adjunto IV da Universidade Federal de Santa Catarina - UFSC. \\ E-mail: clarice.fortkamp.caldin@ufsc.br
}

Priscila Machado Borges Sena

Doutoranda em Ciência Informação pela Universidade Federal de Santa Catarina - UFSC.

E-mail: priscilasena.ufsc@gmail.com

\begin{abstract}
Jéssica Bedin
Doutoranda no Programa de Pós-Graduação em Ciência da Informação na Universidade Federal de Santa

Catarina - UFSC.

E-mail: jessicabedin06@gmail.com
\end{abstract}

\section{Resumo}

Entende-se por literatura infantil a narrativa que cativa crianças e instiga o imaginário infantil. Lembra-se que o movimento de acesso aberto, voltado inicialmente para a produção acadêmica, ganha força em outras esferas, entre elas, a produção literária voltada ao público infantil. Objetiva-se neste artigo analisar as vantagens e desafios da literatura infantil em acesso aberto. Trata-se de uma pesquisa de caráter exploratório, por aproximar as temáticas de literatura infantil e acesso aberto. Para a análise dos sites utilizaram-se dois focos: uma observando-se a estrutura dos sites, e outra as histórias disponíveis. Conclui-se que as vantagens do acesso aberto da literatura infantil são: disponibilização de histórias em domínio público; variedade de formas proporcionadas pelas tecnologias para o formato digital e eletrônico; abrangência de público. Em relação aos desafios a superar destacase: preocupação com os direitos autorais; elaboração mais atrativa dos textos e das ilustrações nos formatos digitais e eletrônicos; falta de incentivo aos autores para produzirem obras literárias infantis em acesso aberto.

Palavras-chave: Literatura infantil. Acesso aberto. Texto literário infantil - formato digital. Texto literário infantil - formato eletrônico. Sites - literatura infantil.

\begin{abstract}
It is understood by children's literature the narrative that captivates children and instigates the child's imagination. It should be remembered that the open access movement, which was initially aimed at academic production, gains strength in other spheres, among them, literary production directed at children. The objective of this article is to analyze the advantages and challenges of children's literature in open access. This is an exploratory research, because it approaches the themes of children's literature and open access. For the analysis of the sites we used two foci: one observing the structure of the sites, and another the available stories. It is concluded that the advantages of open access to children's literature are: providing stories in the public domain; variety of forms provided by technologies for the digital and electronic format; audience. In relation to the challenges to be overcome, we highlight: concern with copyright; more attractive preparation of texts and illustrations in digital and electronic formats; lack of incentive for authors to produce children's literary works in open access.
\end{abstract}

Keywords: Children's literature. Open access. Children's literary text - digital format. Children's literary text electronic format. Children's literature sites. 


\section{Introdução}

Os benefícios da Literatura Infantil no desenvolvimento infantil são inúmeros, pois as histórias permitem o contato com universos totalmente distintos, levando a criança a experimentar o diferente sem sair do lugar. Nessa perspectiva, as tecnologias de informação e comunicação vêm alavancando o potencial benéfico da Literatura Infantil, uma vez que, abre um leque ainda maior de possibilidades para instigar o imaginário, reduzindo questões de tempo e espaço.

O imaginário, antes instigado apenas com o livro impresso, ganha forma em versões digitais e eletrônicas dialogando com esse público leitor cada vez mais esperto e exigente. Esclarece-se que livros digitais são aqueles que estão disponíveis na web em versões html, txt ou pdf e para lê-los é preciso dispor e um computador conectado à rede e um programa de navegação, entre os quais estão Internet Explorer, Mozilla Firefox, Google Chrome, Apple Safari, Opera, entre outros (ODDONE,2013). Já livros eletrônicos são aqueles disponíveis em versões epub, mobi, azw e ios, entre outras; para lê-los é necessário localizar websites especializados, baixar arquivos com o conteúdo dos livros e fazer upload desses arquivos em aparelhos como Kobo, Kindle e iPad, entre outros (ODDONE, 2013). Não é o caso de se desprezar os textos impressos, porém é inegável os horizontes que se abrem com as novas versões, propiciadas pela tecnologia.

Grande parte da repercussão das versões digitais e eletrônicas se deve ao contexto da sociedade atual. Crianças que já nascem com um universo tecnológico ao seu dispor, cada vez mais cedo conectam-se a tablets e smartphones, tendo a possiblidade de acessar o mundo por intermédio desses dispositivos, inclusive os livros digitais que lhes atraem - principalmente os disponíveis em acesso aberto.

Cabe lembrar que o movimento acesso aberto, inicialmente era voltado para a produção acadêmica, mas cada vez mais ganha força em outras esferas, entre elas, a produção literária voltada ao público infantil. Assim, este artigo objetiva analisar as vantagens e desafios da literatura infantil em acesso aberto a partir da realidade encontrada.

Para tanto, apresentam-se neste artigo os seguintes tópicos: Procedimentos metodológicos, Literatura infantil, Acesso aberto, a Literatura infantil em acesso aberto (abordando os dados e a análise deles) e as Considerações finais. 


\section{Procedimentos metodológicos}

No que se refere aos procedimentos metodológicos trata-se de uma pesquisa de caráter exploratório, por aproximar as temáticas de literatura infantil e acesso aberto, além de analisar um recorte de sites, com o intuito de explorar como se encontra o cenário da literatura infantil em acesso aberto.

Assim, apresenta-se o mapeamento da literatura infantil existente em acesso aberto nos idiomas português e espanhol. O que permitiu a recuperação de sites na América Latina e Europa.

Para localizar os sites em português e espanhol realizou-se uma busca simples no Google, utilizando as palavras-chave "histórias infantis" e "cuentos infantiles". Selecionou-se 14 sites para a análise da literatura infantil em acesso aberto.

Pós-mapeamento, arrolou-se os sites que possuíam literatura infantil em Acesso Aberto nos idiomas selecionados para finalmente, verificar as vantagens e os desafios da disponibilização do material encontrado.

Individualmente se explorou cada um dos sites quanto aos recursos ofertados, sendo a análise com dois focos: estrutura e histórias disponíveis. Ao analisar a estrutura do site observou-se a organização, layout, quantidade de propagandas, informações disponíveis e autoria.

Torna-se pertinente observar ainda, que quanto a estrutura do site verificou-se sua organização e apresentação, no que se refere ao caminho que pode viabilizar ou não uma navegação mais agradável a facilitar a recuperação das histórias, sem falar no quesito mais importante, uma leitura prazerosa.

No que concerne à análise das histórias disponíveis nos sites, analisou-se os tipos de histórias, formato de apresentação, ilustração e autoria. A forma como as histórias são apresentadas pode influenciar diretamente na leitura, principalmente por se tratar de histórias para crianças, a simplicidade na apresentação e os detalhes na escrita e ilustrações faz-se fundamental para cativar a atenção e dar asas a imaginação.

A seção a seguir apresenta o embasamento teórico sobre a temática literatura infantil, oportunizando uma análise mais consistente ao observar os sites. 


\section{Literatura infantil}

É comum a dificuldade entre os autores de definir o que é Literatura Infantil. Caldin (2010, p. 53), observa que "há quem diga que é um gênero menor, uma forma simples, cultura de massa, alienação da realidade, indústria editorial, pedagógica, entre tantas outras afirmativas preconceituosas".

Entretanto, é bom lembrar que, subsidiária da "grande literatura", a literatura infantil é arte, e fabulação, narrativa voltada para instigar a imaginação, despertar o desejo de ler e, acima de tudo, permitir a ebulição das emoções.

Como bem disse Meireles (1984, p. 20):

[...] tudo é uma Literatura só. A dificuldade está em delimitar o que se considera como especialmente do âmbito infantil. São as crianças, na verdade, que o delimitam, com a sua preferência. Costuma-se classificar como Literatura Infantil o que para elas se escreve. Seria mais acertado, talvez assim classificar o que elas leem com utilidade e prazer.

Mas a visão adultocêntrica está presente na Literatura Infantil, como mostra Hunt (2010):

[...] no caso dos livros para crianças, não podemos fugir ao fato de que são escritos por adultos, de que haverá controle e estarão envolvidas decisões morais. Da mesma forma, o livro será usado não para acolher ou modificar nossas opiniões, mas para formar as opiniões das crianças. Assim, os tipos de leitura que os textos para crianças recebem delas envolvem aquisição da cultura e da língua. (HUNT, 2010, p. 85, grifo do autor).

Oliveira (2005, p. 50) afirma que existe um contrato de comunicação entre o escritor e o público ("conjunto de convenções"); baseado no interesse desse último, o primeiro elabora um projeto de comunicação (constituído das "intenções", dos objetivos" e das "estratégias" do autor); dessa feita, tanto o contrato como o projeto de comunicação se adequam ao gênero textual e variam, dependendo da categoria do texto. Para Oliveira (2005), a diferença entre a literatura para adultos e a literatura para crianças está pautada apenas na diferença de público. Assim, tendo em vista algumas particularidades da infância: "limitações de léxico, de sintaxe e de visão do mundo", o escritor tem pouca "margem de manobra" - menos liberdade linguística para a narrativa - o que aumenta "o seu desafio" (OLIVEIRA, 2005, p. 58).

Reforça Ramos (2005, p. 148): "Brilhante é o escritor que consegue captar o imaginário infantil [...] e se comunicar diretamente com a alma da criança [...]". 
Então, muito embora o texto literário voltado ao público infantil esteja permeado de elementos com propósitos educativos e sociais (valores da sociedade), como ficção que é, prioriza o belo e o agradável - seja na narratividade, seja nas ilustrações. Para que as crianças sejam cativadas pelo livro, entretanto, há que se apresentar a elas textos instigantes e prazerosos, interessantes, marcados por componentes de verossimilhança mesclados com a fantasia e ilustrações que comunguem com o texto, que complementem a narrativa.

Tendo claro o que distingue a Literatura Infantil da literatura para adultos, as características do literário permanecem as mesmas. Caldin (2010) lista as seguintes: função estética, ficção, colocação em primeiro plano da linguagem, intemporalidade, universalidade, engajamento, linguagem falante, e literariedade.

Quanto à tipologia das histórias para crianças, as mesmas podem ser classificadas em mitos, lendas, contos de fadas, fábulas, histórias de animais, folclore, contos contemporâneos, histórias maravilhosas modernas, poesia, teatro.

Mitos são a representação do pensamento mágico; lendas se valem de um fato que aconteceu, transformado e ampliado pela voz do povo; contos de fadas se caracterizam pela fórmula era uma vez... e pelo final feliz; fábulas contêm uma lição de moral explícita, em que animais se comportam como humanos; histórias de animais, ao contrário, subliminarmente apresentam a moral aceitável socialmente, e os bichos não necessariamente agem como pessoas; folclore - para crianças é traduzido, na maioria das vezes, como adivinhas, versos para brincar, trava-línguas e contos de esperteza; contos contemporâneos costumam apresentar aspectos da realidade atual, cujos protagonistas são crianças que resolvem seus problemas do cotidiano sem a interferência dos adultos; histórias maravilhosas modernas fundem o real com o maravilhoso; poesia é a narrativa versificada, lírica, que enseja a introspecção; teatro entrelaça texto, gestualidade, dança, música, cenário (CALDIN, 2010).

Sob a égide de qualquer tipologia, a literatura infantil possibilita que as crianças descubram o mundo e seus encantamentos. Além de auxiliar a entender a realidade, permite-as viajar entre realidade e fantasia, sonhos e desejos.

Lembrando que o maravilhoso tem papel fundamental na formação do espírito infantil, Coelho (2000, p. 54-55), baseando-se na psicanálise, defende os contos de fadas como “decisivos para a formação da criança em relação a si mesma e ao mundo à sua volta", pois o "maniqueísmo que divide as personagens em boas e más, belas ou feias, poderosas ou fracas, 
etc. facilita à criança a compreensão de certos valores básicos da conduta humana ou do convívio social.".

Conquanto seja inegável a contribuição dos contos de fadas para o enfrentamento dos medos/ inseguranças das crianças ou ameaças do mundo exterior, as demais histórias infantis, pela linguagem metafórica, ludismo, presença de personagens atuantes, situações tristes ou engraçadas, final inusitado - permitem também o desabrochar ou o fortalecimento da imagética e satisfazem as necessidades estéticas das crianças.

Lembra Azevedo (2005, p. 25), entretanto, que “[...] temos, no Brasil, poucas bibliotecas, poucas livrarias e livros caros para os padrões de renda da maioria da população.”

Dessa feita, material ficcional disponibilizado em acesso aberto, sem custos, pode ser considerado valioso para disseminação e leitura da literatura infantil.

\section{Acesso aberto}

Para compreender melhor o quanto o acesso aberto pode favorecer a difusão da literatura infantil, é válido abordar alguns pontos importantes de seu histórico que remonta há mais de 30 anos, desde a década 1970, tornando-se mais notório ao final da década de 1990, conforme é apresentado na sequência.

Fausto (2018, p. web), em uma compilação dos acontecimentos mais relevantes para o movimento acesso aberto aborda seu histórico antes das principais iniciativas ocorridas na década de 90.

4 de julho de 1971: Lançado o Projeto Gutenberg (Gutenberg Project) por Michael Hart

1989: lançada a revista de acesso livre online Psycoloquy por Stevan Harnad, que se tornou revisada por pares em janeiro de 1990.

Agosto de 1989: lançada a revista online de acesso livre The Public-Access Computer Systems Review, por Charles W. Bailey Jr, que se tornou revisada por pares em abril de 1992.

O Projeto Gutenberg foi a primeira e maior coleção unitária de livros eletrônicos gratuitos, ou eBooks, fundado por Michael Hart, que em 1971 inventou esse tipo de livro, continuando a inspirar a criação de eBooks e tecnologias relacionadas a estes (PROJETO GUTENBERG, 2008).

A Psycoloquy é uma revista eletrônica internacional interdisciplinar amparada pela American Psychological Association (APA). Posto isso, publica artigos de alvo e comentários 
de pares em todas as áreas da psicologia, bem como ciência cognitiva, neurociência, biologia comportamental, inteligência artificial, robótica/visão, linguística e filosofia (UNIVERSITY OF SOUTHAMPTON, [20--]).

The Public-Access Computer Systems Review foi a primeira revista de acesso aberto na área de biblioteconomia e da ciência da informação. Dessa forma, abrange temáticas relacionadas a bibliotecas digitais, publicações eletrônicas, internet e catálogos on-line (THE PUBLIC-ACCESS COMPUTER SYSTEMS REVIEW, [199-]).

Porém, é no final da década de 1990 que manifestações, como a criação da Iniciativa dos Arquivos Abertos (Open Archives Initiative - OAI) a favor do acesso aberto, começaram a ganhar força e notoriedade. A iniciativa surgiu com o objetivo de defender o acesso livre, gratuito e irrestrito dos resultados de pesquisas científicas e/ou acadêmicas via WEB (KURAMOTO, 2006; SANTOS JÚNIOR, 2010; SAYÃO, 2010; RODRIGUES; OLIVEIRA, 2012).

De acordo com Rodrigues e Oliveira (2012, p. 80), a premissa do movimento a favor do acesso aberto é que todas as publicações que utilizam recursos públicos devem estar disponíveis para todos, sem qualquer custo adicional. Porém, o acesso aberto gera outras necessidades, como a regulamentação dos direitos autorais das obras publicadas na Internet (RODRIGUES; OLIVEIRA, 2012).

Sobre a regulamentação dos direitos autorais, Machado (2005) já havia abordado que o movimento acesso aberto é parceiro de outras iniciativas, como o Creative Commons, que abarca principalmente as publicações com alicerce em suportes digitais disponíveis na Internet, e o software livre.

O projeto Creative Commons, concebido inicialmente nos Estados Unidos, foi idealizado exatamente para suprir essa necessidade de regulamentação dos direitos autorais, objetivando "fornecer instrumentos legais padronizados para facilitar a circulação e acesso de obras intelectuais tanto na Internet quanto fora dela" (BRANCO; BRITO, 2013, p. 19). Por meio de licenças públicas padronizadas são estabelecidos direitos concedidos, facilitando o acesso, compartilhamento, modificação e distribuição de obras intelectuais na rede (BRANCO; BRITO, 2013).

Segundo Nassi-Calò (2016, p. web): 
Decorridos 15 anos, o acesso aberto se consolida como modelo de negócios e política de publicação de resultados de pesquisa financiada com recursos públicos em todo o mundo, apoiada por mandatos de instituições, agências de fomento e tomadores de decisão.

Essa consolidação fez o acesso aberto tornar-se uma alternativa atraente também para outras esferas de publicações. Uma delas é a literatura infantil em razão de trazer a possibilidade de acesso a livros infantis de qualidade, sendo instrumento importante na construção de uma sociedade leitora.

Para Machado (2005), o acesso aberto à literatura deve ser entendido como a disposição livre e pública na Internet, de maneira a possibilitar a todos os tipos de usuários "[...] a leitura, download, cópia, impressão, distribuição, busca ou o link com o conteúdo completo de artigos, bem como a indexação ou o uso para qualquer outro propósito legal.”.

Atualmente, é possível encontrar diversas histórias antes só acessíveis por meio de livros impressos ou mídias pagas, disponíveis em sites com acesso aberto. Na seção a seguir é apresentado um rol dos sites que possuem literatura infantil em acesso aberto, selecionados para ser analisados mediante suas vantagens e desafios.

\section{A literatura infantil em acesso aberto}

O acesso aberto pode beneficiar a elaboração e disseminação de livros digitais e eletrônicos, já que estes podem oferecer menor custo de fabricação, e garantem o livre acesso a um número ilimitado de pessoas. Disseminar histórias para crianças de forma gratuita tornase um dos atrativos no setor de literatura infantil. No decorrer desta seção, apresentar-se-ão iniciativas de sites que disponibilizam histórias em acesso aberto para o público infantil.

Como já explicado, para localizar os sites realizou-se uma busca simples no Google, utilizando as palavras-chave "histórias infantis" e "cuentos infantiles". Selecionou-se 14 sites para a análise da literatura infantil em acesso aberto conforme apresentado no quadro 1. 
Quadro 1 - Relação de sites relevantes de literatura infantil em acesso aberto

\begin{tabular}{|c|c|c|c|c|c|c|}
\hline Item & Nome da página & Formato & Idioma & Pais & $\begin{array}{l}\text { Quantidade } \\
\text { aproximada } \\
\text { de histórias }\end{array}$ & Link de acesso \\
\hline 1 & Portal Biblon & Portal & Português & Portugal & 144 & http://www.portal-biblon.com/ \\
\hline 2 & Cantinho da Criança & Blog & Português & Brasil & 76 & $\begin{array}{l}\text { http://algumashistoriasinfantis.blo } \\
\text { gspot.com.br/ }\end{array}$ \\
\hline 3 & Domínio público & $\begin{array}{l}\text { Biblioteca } \\
\text { Virtual }\end{array}$ & Português & Brasil & 22 & $\begin{array}{l}\text { http://www.dominiopublico.gov.b } \\
\text { r/pesquisa/ResultadoPesquisaObra } \\
\text { Form.do?first=50\&skip=0\&ds_tit } \\
\text { ulo=\&co_autor=\&no_autor=\&co_- } \\
\text { categoria=33\&pagina=1\&select_a } \\
\text { ction=Submit\&co_midia=2\&co_o } \\
\text { bra=\&co_idioma=1\&colunaOrden } \\
\text { ar=null\&ordem=null }\end{array}$ \\
\hline 4 & Histórias em português & Blog & Português & Brasil & 190 & $\begin{array}{l}\text { https://contadoresdestorias.wordpr } \\
\text { ess.com/historias- } 2 /\end{array}$ \\
\hline 5 & Histórias Era Uma Vez & Blog & Português & Brasil & 43 & $\begin{array}{l}\text { http://historiasinfantilparacriancas } \\
\text {.blogspot.com.br/ }\end{array}$ \\
\hline 6 & $\begin{array}{l}\text { Histórias para os mais } \\
\text { pequeninos e para os } \\
\text { menos pequeninos }\end{array}$ & Blog & Português & Brasil & 34 & $\begin{array}{l}\text { https://historiasparaosmaispequeni } \\
\text { nos.wordpress.com/caixinha-das- } \\
\text { historias/para-3-6-anos/ }\end{array}$ \\
\hline 7 & Histórias Infantis & Blog & Português & Brasil & 384 & http://www.historias-infantis.com/ \\
\hline 8 & Mundo Primaria & Portal & Espanhol & Espanha & 294 & $\begin{array}{l}\text { http://www.mundoprimaria.com/c } \\
\text { uentos-infantiles-cortos/ }\end{array}$ \\
\hline 9 & Chiquipedia & Portal & Espanhol & Espanha & 126 & http://www.chiquipedia.com/ \\
\hline 10 & Cuentos para dormir & Portal & Espanhol & Espanha & 320 & http://cuentosparadormir.com/ \\
\hline 11 & Pequelandia & Blog & Espanhol & Espanha & 105 & $\begin{array}{l}\text { http://www.pequelandia.org/cuent } \\
\text { os/ }\end{array}$ \\
\hline 12 & Los mejores cuentos & Blog & Espanhol & Espanha & 20 & $\begin{array}{l}\text { http://www.losmejorescuentos.co } \\
\text { m/cuentos/cuentosinfantiles.php }\end{array}$ \\
\hline 13 & Cuentos Infantiles & Blog & Espanhol & Espanha & 180 & $\begin{array}{l}\text { http://www.cuentosinfantilesador } \\
\text { mir.com/ }\end{array}$ \\
\hline 14 & Cuentos Infantiles & Blog & Espanhol & Espanha & 35 & http://www.cuentosinfantiles.net/ \\
\hline
\end{tabular}

Fonte: Elaborado pelas autoras, 2017.

Analisaram-se sete sites em português, sendo seis brasileiros e um de Portugal, nos quais foram encontrados dois tipos de estruturas, no formato de portal com informações bem organizadas, o que facilita a navegação e escolha das histórias, apresentando layout agradável e limpo. E em sua grande maioria no formato blog, o que dificulta a navegação por concentrar um número grande de informações em uma estrutura simples sem muitos ícones de navegação. Registra-se que as propagandas ocupam muito espaço e deixam a página poluída, o que atrapalha a leitura tirando o foco da história. 
Os portais que geralmente são mantidos por instituições, deixam claro suas autorias e seus propósitos. Já a autoria nos blogs não aparece tão claramente, o que acaba deixando-os sem credibilidade e gerando alguns questionamentos: Quem é o autor da página? Qual o propósito da página? Essas informações são confiáveis?

As histórias disponíveis nos sites são inúmeras. Encontrou-se desde as clássicas (Ex: Cinderela, Branca de Neve e os Sete Anões, com diversas abordagens e visões), contos populares, fábulas, lendas (de diversos países), poesias, contos de fadas, histórias com moral, histórias que permitem às crianças viajarem no imaginário e desenvolver a capacidade de reflexão, uma vez que a diversificação de tipologias e diferentes abordagens das histórias estimulam o intelecto e satisfazem as necessidades estéticas - pode-se mesmo dizer que aguçam o emocional despertado pela imagética, desde que contenham enredo atraente e personagens que permitam a identificação. Além disso, é importante frisar que ilustrações e formato facilitam ou dificultam a leitura e podem ser indicativos de bom ou mal layout.

Quanto às histórias clássicas, estas aparecem com maior frequência nos sites, por estarem em domínio público. Havendo assim, um número ainda pequeno de histórias mais contemporâneas, o que se deve provavelmente pelo fato dos autores ainda não terem o hábito e/ou incentivo de publicar no formato digital em acesso aberto.

Histórias com enredo atraente foram encontradas, porém a forma de apresentação tende a prejudicar a leitura, tornando-a um processo enfadonho e desagradável. Ao realizar a leitura percebeu-se a falta de palavras ou palavras escritas de forma errada. Verificou-se que os blogs disponibilizam um grande número de histórias que não instigam a imaginação. Além disso, a maneira como são apresentadas as histórias: textos longos, excesso de propaganda e ilustrações sem atrativos - não cativam as crianças.

Quando se trata literatura infantil logo vem a ideia de livros coloridos, cheios de desenhos e criatividade. Porém, os sites encontrados disponibilizam as histórias no formato texto corrido, não existindo uma preocupação com as imagens e formatos, o que deixa a desejar ao se tratar de literatura infantil, dificultando a leitura e deixando-a cansativa, sem fluidez.

Com uma infinidade de opções para o lazer disponível na internet, a criança provavelmente não se sentirá atraída por esse tipo de material, sem um diferencial de qualidade.

No idioma espanhol, selecionou-se sete sites, e ao realizar a analise verificou-se que os todos são oriundos da Espanha. Durante a análise dos sites foram encontrados também dois 
tipos de estruturas. No formato portal as informações apresentaram-se bem organizadas, contando com menus que facilitam a navegação e garantem uma visão geral do que pode ser encontrado, oferecendo layout agradável e limpo com poucas propagandas. E no formato blog com estruturas mais simples, com pouca ou nenhuma organização, propagandas ocupando maiores espaços, e conteúdos perdidos em meio a inúmeras e diversas informações.

Nos portais espanhóis percebeu-se clareza quanto à autoria da página e seu propósito, destacando o cuidado com os direitos autorais, disponibilizando apenas materiais de domínio público e informações sobre esses temas. Ademais, notou-se que estes identificam-se como portais educacionais que se preocupam com a educação de qualidade e gratuita.

Já nos blogs não se encontrou nenhuma informação sobre autoria e identificação da página, apenas disponibilização as histórias. Existe uma variedade de tipologias de histórias, porém as mesmas acabam se repetindo por serem de domínio público.

O destaque ficou para as histórias clássicas, para dormir, populares, de fada, de terror, com valores, e famosas. O site "Cuentos para dormir" merece relevância, pois foi o único que disponibiliza histórias ilustradas no formato e-book, escritas pelo próprio autor do site. $\mathrm{Na}$ Figura 1 é possível visualizar a qualidade dos e-books disponíveis. 
Entonces se dio cuenta de lo mal que había tratado a sus amigos los juguetes, así que les pidió perdón y desde aquel día siempre ¿COstó a sus juguetes en sus sitios faverites antes de dormir.

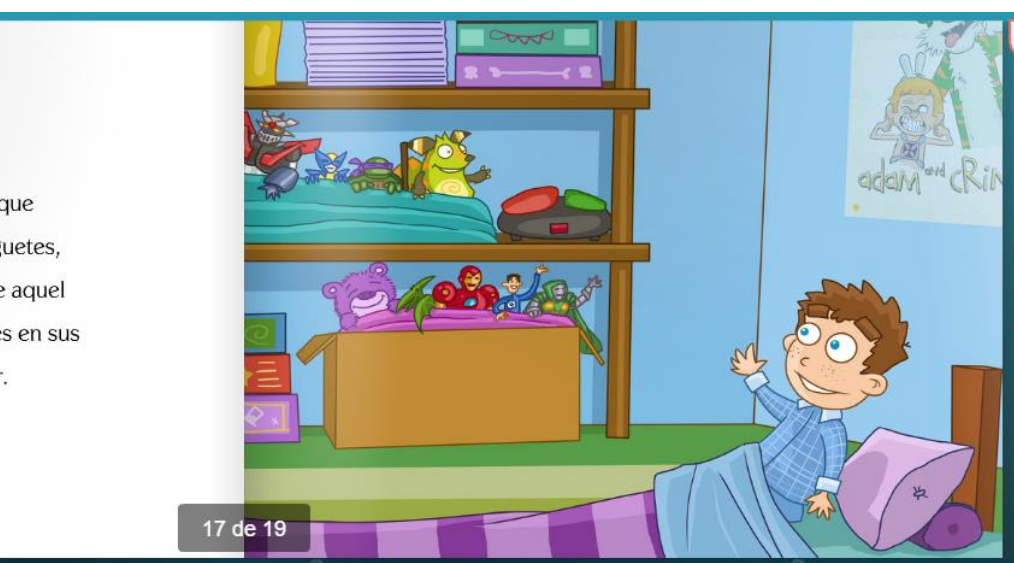
palabras; ¡servían para algo! Después de tantísimos años, resulta que podían hacer más cosas de las que habían creído, y sin asustar ni molestar a los niños. Ese mismo día abandonaron la cárcel dispuestos a crear

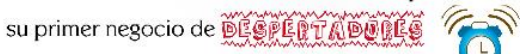

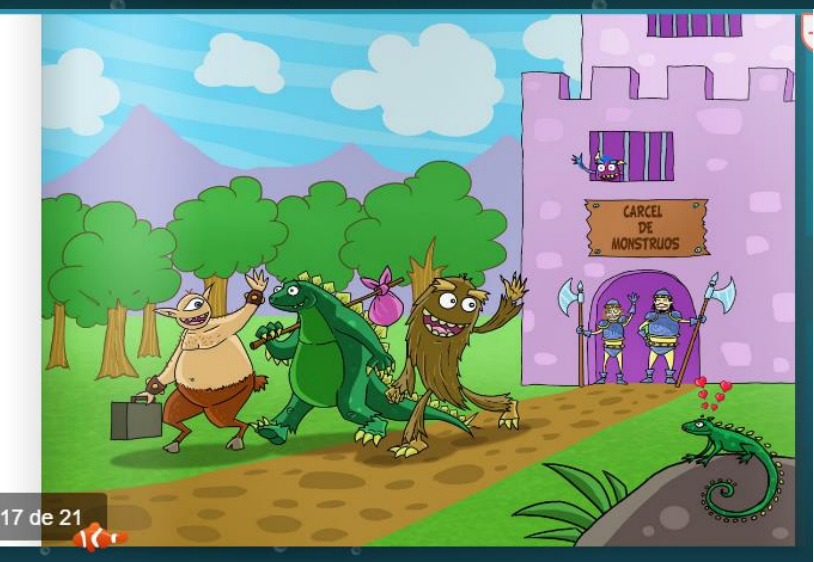

Figura 1 - E-book disponibilizado em Cuentos para dormir Fonte: SACRISTAN, 2018.

Os e-books utilizam tecnologias atuais para apresentar e disponibilizar as histórias. Ao passar as páginas se tem a impressão de folhear um livro impresso; isso causa uma sensação de interação com a história. Outro fator que merece destaque, é que o formato potencializa a história, o leitor fica concentrado no enredo, não tendo propaganda comercial ou outras informações que possam tirar a atenção do leitor, o destaque é a história, é o e-book.

Relacionando as análises dos sites e blogs em português e espanhol, pode-se inferir que durante a navegação nos sites, histórias interessantes foram encontradas, porém a forma de apresentação desmotiva a leitura, principalmente para as crianças, pois a parte visual não é atrativa.

Ainda quanto à forma, percebe-se um enorme descuido na divulgação das histórias em relação aos direitos autorais, pois em sua grande maioria não apresentam o autor, nem a data; o que remete a uma falta de preocupação quanto a disponibilização de uma literatura infantil de qualidade.

A seguir, apresenta-se no Quadro 2 uma síntese das vantagens e desafios da literatura infantil em acesso aberto. 
Quadro 2 - Relação de sites relevantes de literatura infantil em acesso aberto

\begin{tabular}{|c|c|}
\hline Vantagens & Desafios \\
\hline $\begin{array}{c}\text { Quantidade de histórias disponíveis e acessíveis } \\
\text { em um mesmo local. }\end{array}$ & Respeito aos direitos autorais. \\
\hline $\begin{array}{c}\text { Garantia do livre acesso, atingindo um número } \\
\text { maior de pessoas. }\end{array}$ & $\begin{array}{c}\text { Plataforma de qualidade para disponibilizar as } \\
\text { histórias. }\end{array}$ \\
\hline Menor custo de fabricação & $\begin{array}{c}\text { Elaboração em formato específico para o meio } \\
\text { digital e/eletrônico, de maneira mais interativa e } \\
\text { envolvente. }\end{array}$ \\
\hline Potencialização do incentivo à leitura. & $\begin{array}{c}\text { Incentivo aos autores para produzirem obras } \\
\text { literárias infantis em acesso aberto. }\end{array}$ \\
\hline & $\begin{array}{c}\text { Uso de tecnologias para disponibilizar os e- } \\
\text { books. }\end{array}$ \\
\cline { 2 - 2 } & $\begin{array}{c}\text { Disponibilizar informações sobre o site, sua } \\
\text { autoria e finalidade, visando garantir a } \\
\text { confiabilidade. }\end{array}$ \\
\hline
\end{tabular}

Fonte: Elaborado pelas autoras, 2017.

De forma geral, as vantagens da literatura infantil em suporte físico podem ser transferidas quando disseminadas em acesso aberto, com ganho de abrangência e de variedade de público, uma vez que mais crianças podem ter contato com esse tipo história. Todavia, defende-se que para a conquista do público infantil nativo digital faz-se necessário mais que disponibilizar histórias da literatura infantil, mas disponibilizá-las com qualidade e cuidado. Fato que corrobora com Meireles (1984), quando chamou a atenção para esse tipo de literatura ser delimitado a partir do que as crianças leem, ou seja, o que preferem ler e não o que os adultos pensam que seja adequado ao público infantil, tornando-se necessária a preocupação com a qualidade do texto e da ilustração.

Existem atualmente sites que oferecem jogos de qualidade para crianças. Seria interessante disponibilizar livros infantis em acesso aberto, já que estes, conforme foi mencionado por Caldin (2010), precisam ser uma narrativa cativante. Posto isso, a união de sites com jogos atraentes e livros infantis pode ser uma forma de cativar o público infantil atual.

As instituições públicas poderiam apoiar os autores de literatura infantil na publicação em acesso aberto, da mesma forma que acontece com as publicações científicas, visando à difusão da leitura e do conhecimento por meio da tecnologia. Um exemplo de apoio seria a reunião ou centralização dos livros digitais em uma plataforma visando o livre acesso tanto para escolas e instituições, como para o público em geral. 


\section{Considerações finais}

A partir da pesquisa realizada é possível perceber a existência de algumas iniciativas de disponibilização da literatura infantil em acesso aberto, que de forma geral apresentam notórias vantagens quanto à disponibilização gratuita de histórias que antes só poderiam ser adquiridas por meio físico e, na maioria das vezes, com algum custo financeiro. No entanto, é perceptível também que os desafios para esse tipo de acesso à literatura infantil são maiores que as vantagens destacadas. O que pode ter relação com o fato de ser recente as iniciativas voltadas para esse setor.

Quanto aos pontos a melhorar, destaca-se principalmente a apresentação dos sites e dos livros, geralmente em PDF. Os sites, como puderam ser observados, são em sua maioria blogs totalmente despadronizados e pessoais. A única base de dados efetiva encontrada foi o Portal Domínio Público, mas que também apresenta seus títulos em PDF.

Explicita-se: a crítica quanto ao PDF é devido este ser apenas a transposição do impresso para o digital, sem o cuidado de elaborar uma nova dinâmica de apresentação da história, desprezando as tecnologias disponíveis para tal. Uma nova dinâmica de apresentação remete ao cuidado com público infantil atual, nativos digitais a serem conquistados para o prazer do imaginário encontrado a cada leitura.

A literatura no meio digital e em acesso aberto é uma lacuna a ser pesquisada e um campo de atuação em potencial. Percebe-se que as histórias necessitam de um cuidado maior no que se refere à apresentação e layout utilizando as tecnologias de ponta (muitas vezes ferramentas gratuitas) para melhorar a qualidade das histórias e assim atrair o público infantil, sendo um convite agradável para a leitura.

Dessa forma, entende-se que o acesso aberto pode, assim, como faz com a produção científica, disponibilizar livre, gratuita e sem barreiras ou restrições financeiras e técnicas, a literatura infantil através da Internet, permitindo que a mesma possa ser lida, impressa, copiada e distribuída sem fins comerciais. O único fator limitante que há para a reprodução e distribuição é o direito do autor sobre a integridade e crédito de sua obra.

$\mathrm{O}$ acesso aberto a livros infantis de qualidade é fundamental para a construção de uma sociedade leitora. A literatura infantil em acesso aberto beneficia a sociedade como um todo, pois elimina as barreiras de preço dos livros aos leitores, disseminando histórias infantis de forma mais rápida e pode estimular o gosto pela leitura. 
Além disso, o acesso aberto da literatura infantil pode ser utilizado como um importante instrumento na formação de indivíduos criativos, participativos, críticos e leitores para a vida toda. Quiçá verdadeiros cidadãos preocupados em integrar a sociedade, fazendo a diferença por onde passam.

Por fim, às crianças deve ser concedida a oportunidade de escolher as histórias que desejam ler. Cabe aos pais, professores e bibliotecários permitir e incentivar esse exercício. Sites de textos infantis têm a vantagem de propiciar essa autonomia aos leitores infantis, podendo apresentar histórias cativantes e envolventes.

\section{Referências}

AZEVEDO, R. Aspectos instigantes da literatura infantil. In: OLIVEIRA, I. (Org.). O que é qualidade em literatura infantil e juvenil?: com a palavra o escritor. São Paulo: DCL, 2005. p. $25-46$.

BRANCO, S; BRITO, W. O que é creative commons?: novos modelos de direito autoral em um mundo mais criativo. Rio de Janeiro: FGV, 2013. 176 p. Disponível em: $<$ http://bibliotecadigital.fgv.br/dspace/bitstream/handle/10438/11461/O\%20que\%20\%C3\%A9 \%20Creative\%20Commons.pdf>. Acesso em 20 jan. 2017.

CALDIN, C. F. Leitura e literatura infanto-juvenil. Florianópolis: CIN/CED/UFSC, 2010.

COELHO, N. N. Literatura infantil: teoria, análise, didática. São Paulo: Moderna, 2000.

FAUSTO, S. Evolução do acesso aberto: breve histórico. SciELO em Perspectiva. 21 out. 2013. Disponível em: <http://blog.scielo.org/blog/2013/10/21/evolucao-do-acesso-abertobreve-historico/>. Acesso em: 13 abr. 2018.

HUNT, P. Crítica, teoria e literatura infantil. São Paulo: Cosac Naify, 2010.

KURAMOTO, H. Informação científica: proposta de um novo modelo para o Brasil. Ciência da informação, Brasília, v. 35, n. 2, p. 91-102, maio/ago. 2006. Disponível em: <http://www.scielo.br/pdf/ci/v35n2/a10v35n2.pdf $>$. Acesso em: 25 jan. 2016.

MACHADO, J. A. S. Difusão do conhecimento e inovação: o acesso aberto a publicações científicas. In: BAUMGARTEN, M. (Ed.). Conhecimento e redes: sociedade política e inovação. Porto Alegre: UFRGS, 2005. Disponível em: <http://www.forumglobal.de/jm/art04-05/jorge_machado-acesso_aberto.html>. Acesso em 2 jun. 2016.

MEIRELES, C. Problemas da literatura infantil. 3. ed. Rio de Janeiro: Nova Fronteira, 1984.

NASSI-CALÒ, L. O acesso aberto como alternativa de sustentabilidade na comunicação científica. SciELO em Perspectiva, 14 jan. 2016. Disponível em: 
$<$ http://blog.scielo.org/blog/2016/01/14/o-acesso-aberto-como-alternativa-desustentabilidade-na-comunicacao-cientifica/>. Acesso em: 2 jun. 2016.

ODDONE, N. Política de acesso aberto para livros digitais e eletrônicos. 2013. Slides da apresentação realizada no XI Encontro Nacional de Ensino e Pesquisa em Informação, 2013. Disponível em: <http://pt.slideshare.net/neoddone/poltica-de-acesso-aberto-para-livrosdigitais-e-eletrnicos $>$. Acesso em: 20 jan. 2016.

OLIVEIRA, I. Contrato de comunicação, projeto de comunicação e qualidade em literatura infantil e juvenil. In: (Org.). O que é qualidade em literatura infantil e juvenil?: com a palavra o escritor. São Paulo: DCL, 2005. p. 47 - 59.

PROJETO GUTENBERG. Sobre nós. 2008. Disponível em: <http://www.gutenberg.org/wiki/PT-PG_Sobre_N\%C3\%B3s >. Acesso em 14 jan. 2018.

RAMOS, A. C. O jogo do faz-de-conta. In: OLIVEIRA, I. (Org.). O que é qualidade em literatura infantil e juvenil?: com a palavra o escritor. São Paulo: DCL, 2005. p. 147-165.

RODRIGUES, R. S; OLIVEIRA, A.B. Periódicos científicos na América Latina: títulos em acesso aberto indexados no ISI e SCOPUS. Perspectivas em Ciência da Informação, Belo Horizonte, v. 17, n. 4, p. 77-99, dez. 2012. Disponível em:

<http://portaldeperiodicos.eci.ufmg.br/index.php/pci/article/view/1593 > . Acesso em: 25 jan. 2016.

SACRISTAN, P. P. Cuentos para dormir. 2018. Disponível em:

<http://cuentosparadormir.com/cuentos-cortos>. Acesso em: 13 abr. 2018.

SANTOS JUNIOR, E. R. Repositórios institucionais de acesso livre no Brasil: estudo delfos. 2010. 177f. Dissertação (Mestrado em Ciência da Informação) - Universidade de Brasília, Brasília, 2010. Disponível em:

<http://repositorio.bce.unb.br/bitstream/10482/5343/6/2010_ErnaniRufinodosSantosJ unior.pdf >. Acesso em: 25 jan. 2016.

SAYÃO, L. F. Repositórios digitais confiáveis para a preservação de periódicos eletrônicos científicos. Ponto de Acesso, Salvador, v. 4, n. 3, p. 68-94, 2010. Disponível em: <http://www.portalseer.ufba.br/index.php/revistaici/article/view/4709/3565>. Acesso em: 25 jan. 2016.

THE PUBLIC-ACCESS COMPUTER SYSTEMS REVIEW. Focus and scope. [199-]. Disponível:

<https://journals.tdl.org/pacsr/index.php/pacsr/about/editorialPolicies\#focusAndScope>. Acesso em 14 jan. 2018.

UNIVERSITY OF SOUTHAMPTON. Hyper Psycoloquy. [20--]. Disponível em: <http://www.cogsci.ecs.soton.ac.uk/cgi/psyc/newpsy?>. Acesso em 14 jan. 2018. 